\title{
Comparative Study of Total Phenolics and Antioxidants in ASTRAGLUS $S T O C K S I I$ by using Methanol, Ethanol and Acetone and to Evaluate its Anti -Inflammatory Activity
}

\author{
Iqra Arshad ${ }^{1}$, Muhammad Ayub Kakar ${ }^{1}$, Attiq-ur-Rehman Kakar²,*, Noor Hassan Kakar ${ }^{1}$, \\ Saeeda Khanam ${ }^{1}$, Rehana Kamal ${ }^{3}$ and Atta Muhammad ${ }^{4}$ \\ ${ }^{1}$ Institute of Biochemistry, University of Balochistan, Quetta, 87300- Pakistan \\ ${ }^{2}$ Department of Chemistry, University of Balochistan, Quetta, 87300- Pakistan \\ ${ }^{3}$ Department of Obstetrics and Gynecology, Bolan University of Medical and Health Sciences, Quetta 87300, \\ Pakistan \\ ${ }^{4}$ Government Boys Degree College Khanozai-86600, Education Department Balochistan, Pakistan
}

\begin{tabular}{|c|c|}
\hline Article's Information & Abstract \\
\hline $\begin{array}{l}\text { Received: } \\
\text { 12.08.2021 } \\
\text { Accepted: } \\
\text { 11.09.2021 } \\
\text { Published: } \\
\text { 30.09.2021 }\end{array}$ & $\begin{array}{l}\text { Astragalus Stocksii a local flowering plant found in Hana Valley, Quetta } \\
\text { Pakistan, used as home medicinal plant form many years. It is an encouraging } \\
\text { source of bioactive compounds and has been conventionally manipulated for the } \\
\text { coverage of several diseases. The present study based on the evaluation of } \\
\text { phenolics, antioxidants and anti-inflammatory activities of Astragalus Stocksiiby } \\
\text { using three different solvents, i.e.; acetone, ethanol and methanol. The results } \\
\text { showed that extraction yield depends upon the type of the solvents used for }\end{array}$ \\
\hline $\begin{array}{l}\text { Keywords: } \\
\text { Astragalus Stocksii } \\
\text { Antioxidants } \\
\text { Anti-inflammatory } \\
\text { DPPH method } \\
\text { TAC method }\end{array}$ & $\begin{array}{l}\text { extraction. Among these, extraction in methanol has the highest phenolic contents } \\
(10.086 \pm 0.08 \mathrm{mg} \text { CE/g DW), total antioxidant capacity (TAC, IC } 50=14.50 \pm 0.01 \\
\mu \mathrm{g} / \mathrm{mL} \text {, phospho-molibdenum method, } \mathrm{IC}_{50}=66.62 \pm 0.03 \mu \mathrm{g} / \mathrm{mL} \text { by DPPH method) } \\
\text { and high anti-inflammatory activity (IC } \mathrm{IC}_{50}=75.0 \pm 2.5 \mu \mathrm{g} / \mathrm{mL} \text {, oxidative burst } \\
\text { assay). These results indicate that methanol is the best solvent for extraction of } \\
\text { phenolic and antioxidants in Astragalus Stocksii. The high results of anti- } \\
\text { inflammatoryfor Astragalus Stocksii suggests its use in pharmaceutical and } \\
\text { nutraceutical industries. }\end{array}$ \\
\hline
\end{tabular}

DOI: $10.22401 /$ ANJS.24.3.03

*Corresponding author: arkakar10@gmail.com

\section{Introduction}

Different species of medicinal plants are worldwide important source for the formation of new drugs as traditional system of medicines continue to be widely practiced on many accounts, population increases, insufficient supply of drugs, proscribed cost of treatment, side effect of several synthetic drugs have increased the use of plants as a source of medicines as a human affliction $[1,29]$.There are number of medicinal plants within this one is Astragalus Stocksii. Astragalus is the largest genus in the Fabaceae family, has 3000 species, about 135 species are present in Pakistan. The majority of these species are used as diuretics and antiperspirants in conventional medicine to treat diabetes, leukaemia, and cardiovascular disease. Beside this certain flavinoids, lanoline acid and linoleic acid are also found in astragalus. This plant has antioxidant, antiinflammatory and antimicrobial activity [2].

Interestingly, many medicinal plants contain large amount of antioxidants like phenolic compounds (flavonoid) apart from vitamin C, E and Carotenoids [3,4].
Antioxidants play an important role in inhibiting as well as scavenging radicals, therefore protects human against various infections such as cardiovascular diseases, immune suppression [5], diabetes and cancer 6]. Antioxidant can control the harmful effects of oxidation stress. Oxidation stress is the set of extracellular and intracellular condition that leads to the formation of reactive oxygen, which cause the damage to the tissues. The excessive formation of free radicals or reactive oxygen species (ROS) in the mitochondria causes oxidative stress. ROS is produced through the electron transport chain $[7,8]$. Reactive oxygen species and free radical produce in human body during metabolism as byproducts. These products are harmful for the body and if they remain in the body, they can damage to the macromolecules such as protein, lipid and DNA [9]. This increases the risk of age-related disorders, atherosclerosis, cancer, inflammation and neurodegenerative diseases. Utilization of antioxidants through supplements and diet can remove the ROS from body and give health welfare. Various studies showed that medicinal plants are the biggest source of the antioxidants and act as reducing agents [10,11]. 


\section{Al-Nahrain Journal of Science}

ANJS, Vol.24 (3), September, 2021, pp. 16-22

Inflammation is an important biological activity which maintains the homeostasis of body. It is essential for the repair of damage tissues and for the conflict of pathogens. Nevertheless, it is also presuming in the creation and the maintenance of many disorders like asthma, rheumatoid arthritis, neurodegenerative disease, type 2 diabetes and chronic inflammatory bowel disease $[12,13,28]$. According to the report, plants are thought to inhibit inflammation by regulating the production of pro-inflammatory molecules. Pro-anti-inflammatory molecules formed during the antiinflammatory process, such as leukocyte adhesion, nitric oxide (NO), and cytokine (TNF- $\alpha$ ), play a critical role in the immune inflammatory response.

Nitric oxide (NO) reacts with free radical like super oxide and produce peroxynitrates which can oxidize low density lipoprotein. Formation of peroxynitrate is caused damaging of cell membrane so the hindrance of proinflammatory molecules is anticipated to have therapeutic value adjacent to anti-inflammatory diseases $[11,14]$.

Extraction process has been manipulated to obtain bioactive compounds. The extraction process' main purpose is to increase the number of target chemicals in order to acquire the greatest biological activity from them $[15,16]$. The extraction procedures utilized, as well as the solvents utilized, has an impact on the biological activities of the resultant extract. Many solvents such as methanol, ethanol and acetone have been used for the extraction of these compounds [16,17]. Although no research has been narrated the influence of the solvent on the biochemical compounds extrication from Astragalus Stocksii.

This study investigated the effects of organic solvents (acetone, ethanol, and methanol) on extraction yield, phenolic, and TAC content. Anti-inflammatory and antioxidant activities were also tested.

\section{Material and Methodology}

Chemicals and instrument: Acetone, Methanol, Ethanol, Magnesium chloride, 2,2-Diphenyl-1-picrylhydrazyl (DPPH), Folin-Ciocalteu, gallic acid, ascorbic acid, calcium chloride, potassium fericynide, sodium acetate, ammonium molybdate and all the other reagents used were of analytical grade. The methanol solvent was removed from the extract using a vacuum rotary evaporator (vacuum rotary evaporator, KARL KOLB, Germany), and the extraction was done using a magnet stirrer (JENWAY-1000 Hot Plate Magnetic stirrer). A homogenizer was utilized to homogenize the sample (Westpoint-1844-JuicerBlenderMincer), Deionized water was used for stocks and standards preparation. Spectrophotometer (Shimadzu, Model UV1700, Japan) was used in the research study.

Identification of plant extract: The plant Astragalus Stocksii was collected from the mountainous areas of Hanna lake valley, Balochistan and taxonomically identified by the botany researcher. The branches of the plant were obtained by removing the leaves and spikes. The resulting plant was washed under the sink water and dried at $60^{\circ} \mathrm{C}$ for $72 \mathrm{~h}$ and then used for experiments.
Preparation of plant extract: A correlative work was carried out to examine how solvents affected the extraction yield, as well as the quality of phenolic, antioxidants, and anti-inflammatory activity. The extract of Astragalus Stocksii was equipped by method of Do et al. $1 \mathrm{~kg}$ plant sample were drowned in methanol, ethanol and acetone with the ratio of $1: 20(\mathrm{w} / \mathrm{v})$ at $60^{\circ} \mathrm{C}$ for $24 \mathrm{~h}$. mixture of the solvents were homogenized by using homogenizer at $60{ }^{\circ} \mathrm{C}$ for $24 \mathrm{~h}$ and filtered by using whatman filter paper 1 , concentrated by using rotary evaporator and freeze up it for $24 \mathrm{~h}$. Extracts were held for furthermore investigations. All of the trails were carried out three times.

Calculation of Extraction Yield: The following is how the extraction yield was calculated:

Extraction yield $(\%)=$ Extract weight after evaporating solvent and freeze-drying/Dry weight of the sample $\times 100$

Total Phenolic, Antioxidant and Anti-inflammatory activity Determination: Absolute methanol, ethanol, and acetone were used to dissolve $1 \mathrm{~g}$ of dried extract obtained by each solvent and later on used for the determination of phenolic, antioxidants and anti-inflammatory activity.

Total Phenolics Content (TPC): The Folin-Ciocalteu assay was used to assess the material [21]. $0.5 \mathrm{~mL}$ of diluted extracts is combined with $5 \mathrm{~mL}$ of $10 \%$ Folin-Ciocalteu reagent, followed by $4 \mathrm{~mL}$ of $2 \% \mathrm{Na}_{2} \mathrm{CO}_{3}$ in the assortment. Methanol, Ethanol and acetone were used as a control. In the research investigation, the combination was incubated at room temperature for $60{ }^{\circ} \mathrm{C}$ and the absorbance was measured at $765 \mathrm{~nm}$ using a spectrophotometer (Shimadzu, Model UV1700, Japan). The measurement was repeated three times and total phenolic activity was measured from gallic acid standard curve and then demonstrated as $\mathrm{mg} / \mathrm{g}$ sample.

Determination of Antioxidant Activity: Mahdi-Pour et al. used the DPPH free radical scavenging method to determine the antioxidant activity of Astragallus Stocksii. $1 \mathrm{ml}$ of each concentration of extract was combined with $1 \mathrm{ml}$ of DPPH solution ( $0.004 \%$ in methanol, ethanol, and acetone) and incubated at $37{ }^{\circ} \mathrm{C}$ for 30 minutes. In this analysis, a spectrophotometer (Shimadzu, Model UV1700, Japan) was used to calculate the absorbance at $517 \mathrm{~nm}$.

Methanol, ethanol and acetone were used as a negative control and calculated as follow:

DPPH scavenging activity $(\%)=\mathrm{A}_{0}-\mathrm{A} / \mathrm{A}_{0} \times 100$ where $\mathrm{A}$ is the absorbance of sample extract and $\mathrm{A}_{0}$ is the absorbance of negative control (0.004 percent DPPH solution). A normal solution of Ascorbic acid was used as a standard solution and extracts concentration delivering 50 $\%$ inhibition $\left(\mathrm{IC}_{50}\right)$ were measured by plotting the grape between reticence percentage of remaining DPPH and sample concentration.

Total antioxidant capacity assay (TAC): The total antioxidant capacity of the extracts was measured by the phosphorrmolybdenum technique by using spectrophotometer, described by the prieto et al. (1999). One millimeter $\left(0.5 \mathrm{mg} \mathrm{mL}^{-1}\right)$ of each sample extract was mixed 


\section{Al-Nahrain Journal of Science}

ANJS, Vol.24 (3), September, 2021, pp. 16-22

with $3 \mathrm{ml}$ of reagent solution (4 $\mathrm{mL}$ Ammonium molybdate, $0.6 \mathrm{M} \mathrm{H}_{2} \mathrm{SO}_{4}$ and $28 \mathrm{mM}$ Sodium Phosphate). The blank solution carried reagent only. Solutions were incubated for $150 \mathrm{~min}$ at $95{ }^{\circ} \mathrm{C}$ and then cooled at room temperature. The absorbance was measured at $517 \mathrm{~nm}$ by using spectrophotometer (Shimadzu, Model UV1700, Japan) was used in the research study.

Total antioxidant activity $(\%)=\mathrm{A}_{0}-\mathrm{A} / \mathrm{A}_{0} \times 100$ where $A$ is the absorbance of sample extract and $A_{0}$ is the absorbance of negative control (3 $\mathrm{ml}$ of reagent solution).

\section{Determination of Anti-Inflammatory Activity} Oxidative Burst Assay using Chemiluminescence Technique: As described by Helfand et al.1982 [18, 26], a luminol-enhanced chemiluminescence experiment was performed. In a nutshell, $25 \mu \mathrm{L}$ of diluted whole blood HBSS++ (Hanks Balanced Salt Solution, containing magnesium and calcium chloride) were incubated in triplicate with $25 \mu \mathrm{L}$ of three different doses of chemicals (1, 10 and $100 \mu \mathrm{g} / \mathrm{mL})$. Control wells received $\mathrm{HBSS}^{++}$and cells, but no compounds. The test was carried out in white half-area 96-well plates that were incubated for 15 minutes at $37{ }^{\circ} \mathrm{C}$ in the luminometer's thermostat chamber. After incubation, each well received $25 \mu \mathrm{L}$ of serum opsonized zymosan (SOZ) and $25 \mu \mathrm{L}$ of luminol, an intracellular reactive oxygen species detecting probe, except blank wells (which contained only HBSS++). In a luminometer, the level of ROS was measured in relative light units (RLU). $\mathrm{IC}_{50}$ value for samples is shown in Figure 4.

\section{Results and Discussion}

The current study's analytical results show that Astragalus Stocksii has antioxidant and anti-inflammatory properties, Tables 1 and 2 show the results. Figures 1-4 illustrate the antioxidant and anti-inflammatory properties of three different solvents. Results of \% yield, Total phenolic content (TPC), Total antioxidant capacity (TAC), DPPH assay and anti-inflammatory are shown in Tables 1 and 2.

\section{Extraction Yields \%}

The use of bioactive chemicals derived from natural sources as effective food to promote human fitness and treat a variety of ailments is gaining traction. In the current study, Astragallus stocksii was manipulated as a derivative metabolite compound such as flavonoids, phenolics. These bioactive compounds are obtained by the various steps like Grinding, milling, homogenization and extraction. Extraction is the most important method for extracting these compounds from plant matter. The method of extraction, temperature, time, the solvent used and the composition of bioactive compounds all have a significant impact on extraction yield. In accordance with these results of researchers, use of the solvent is one of the essential stipulations $[16,19]$.

In the current investigation organic solvents such as methanol, ethanol and acetone were used to indentify the anti-inflammatory and antioxidant behavior. Results showed that different solvents have different antioxidant capacity due to the ability to dissolve differently in plant extract [19]. This could be due to the presence of high polarity compounds in plant extract that are soluble in high polarity solvents [20]. It was observed that methanol extract has highest level of bioactive compounds because of higher solubilty in methanol than the other solvents use to identify the affect of solvents. Collectively, these observations indicate that for the extraction of bioactive compounds, methanol is the best solvent [19]. It has been estimated that extraction solvent affect the quantity of bioactive compounds and extraction yeilds so crucially, affect the biological activity of extract $[21,22]$.

Table 1. Percent extraction yield of Asragalus Stocksii in different solvents.

\begin{tabular}{|c|c||}
\hline Solvent & Extraction yield \% \\
\hline \hline Methanol & $30.0 \pm 0.498$ \\
\hline Ethanol & $24.4 \pm 0.374$ \\
\hline Acetone & $18.1 \pm 0.216$ \\
\hline
\end{tabular}

Data are mean \pm SD $(n=3 \times 3)$.

Table 2 indicates the results of different methods applied for the determination of antioxidants and anti-inflammatory activity. Current study suggests that methanolic extract of Astragalus Stocksii has high phenolic, antioxidant and antiinflammatory activity, demonstrating that, among the solvents studied, methanol is the best solvent for identifying bioactive components, and therefore methanol plant extract is a viable antioxidant and anti-inflammatory representative for the pharmaceutical and nutraceutical sectors.

Table 2. Phenolic, antioxidant and anti-inflammatory content of Astragalus Stocksii after exposure to various solvents.

\begin{tabular}{|c|c|c|c|c||}
\hline & & \multicolumn{3}{|c|}{ IC50 \pm SD } \\
\hline Extraction Solvent & $\begin{array}{c}\text { Phenolics (TPC) } \\
\text { CE/g DW }\end{array}$ & $\begin{array}{c}\text { Antioxidant capasity } \\
\text { (TAC) }\end{array}$ & DPPH Assay & Anti-inflammatory \\
\hline Acetone & $7.5 \pm 0.04$ & $9.25 \pm 0.17$ & $59 \pm 0.69$ & $20.3 \pm 1.5$ \\
\hline Ethanol & $8.25 \pm 0.09$ & $11.5 \pm 0.5$ & $60 \pm 0.6$ & $27.3 \pm 4.7$ \\
\hline Methanol & $10.086 \pm 0.08$ & $14.5 \pm 0.01$ & $66.62 \pm 0.03$ & $75 \pm 2.5$ \\
\hline
\end{tabular}

All data are reported as Mean $(n=3) \pm$ SD. 


\section{Al-Nahrain Journal of Science}

ANJS, Vol.24 (3), September, 2021, pp. 16-22

\section{DPPH method}

In order to perceive about the solvent affect, current study was performed to understand the antioxidant and anti inflammatory of Astragallus Stocksii with methanol, ethanol and acetone. In this study, DPPH Method, one of the most comon and reliable method was applied to measure the antioxidant activity. Amongest the different extracts, methanol was the most influential in term of $\mathrm{IC}_{50}$ value of DPPH scavenging activity than that of ascorbic acid. This could be because extract has high value of phenolic, flavinoid and alkoid contents and have powerful antioxidant activity which can inhibit the production of reactive oxygen species, hydroxyl radical superoxide and peroxynitrates [23].

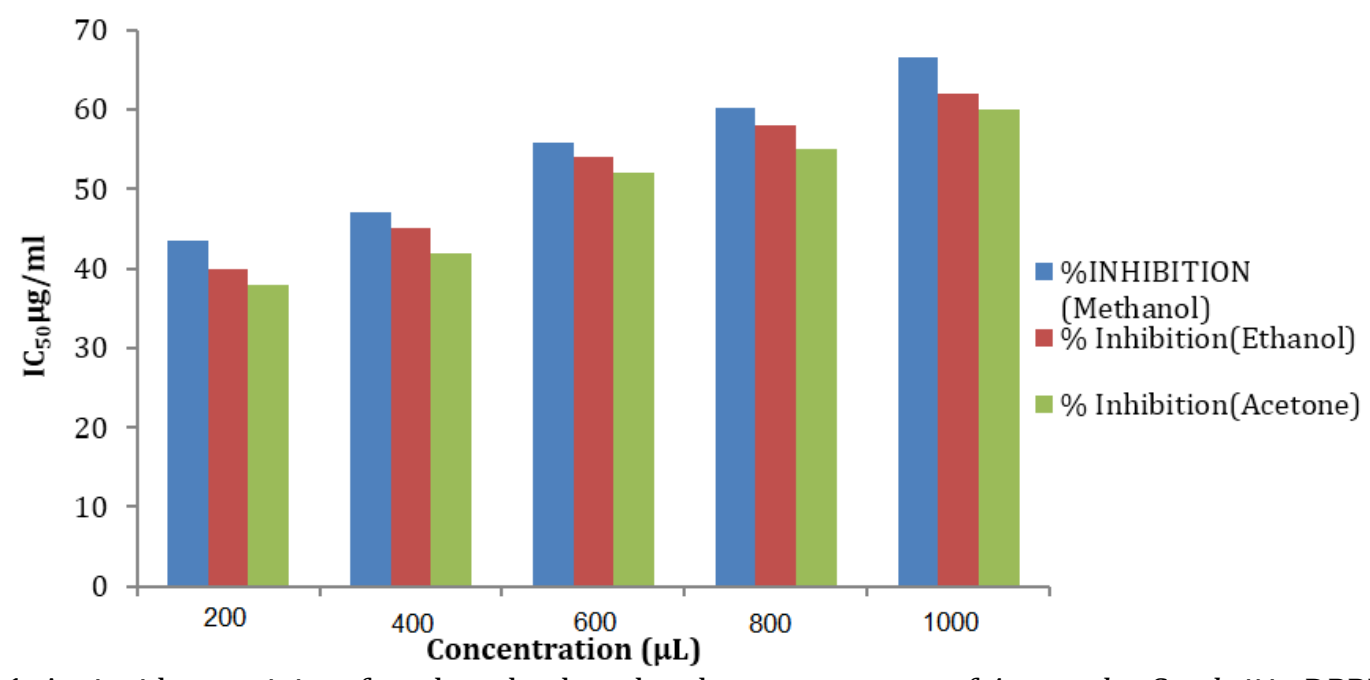

Figure 1. Antioxidant activity of methanol, ethanol and aceton extracts of Astragalus Stocksii in DPPH Assay.

\section{Total phenol contant}

Figure 2 depicts total antioxidant capacity in methanol, ethanol, and acetone. The graph revealed that the concentration of methanol extract is substantially higher than that of ethanol and acetone. Acetone's phenolic content was lower than that of methanol and ethanol. These findings suggest that Astragallus Stocksiii methanolic extract is an effective antioxidant negotiator.

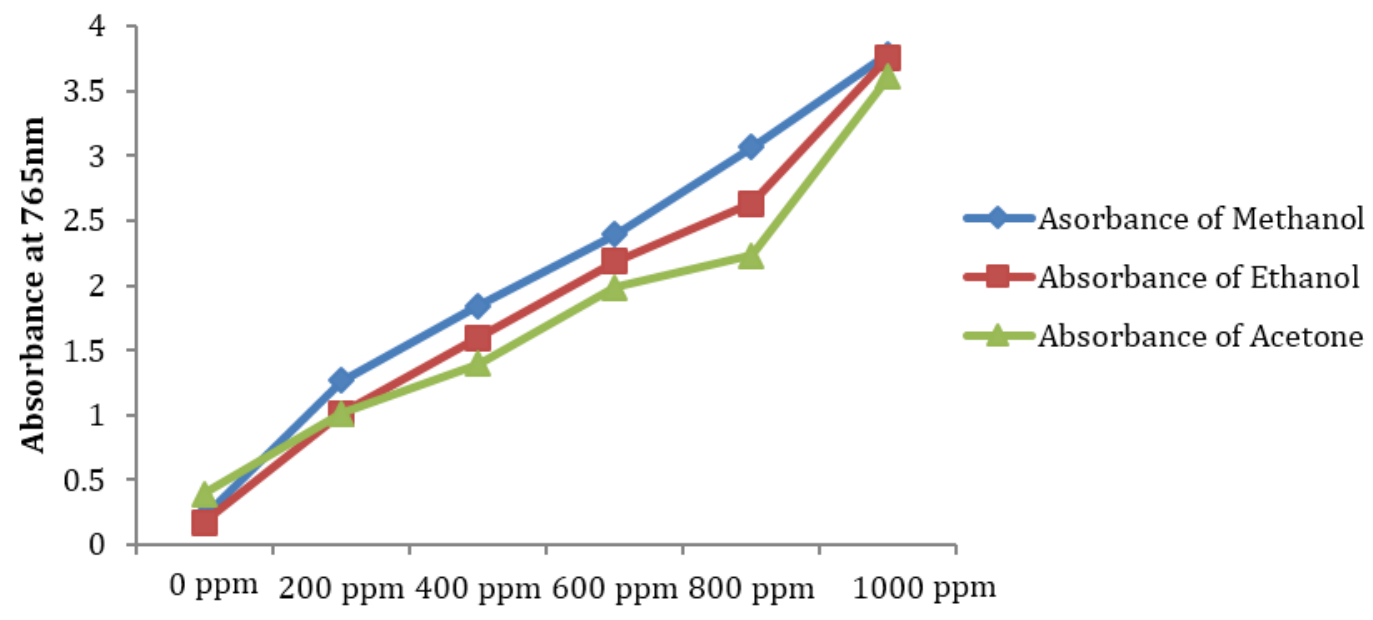

Concentration (ppm)

Figure 2. Total Phenolic content of methanol, ethanol and aceton extracts of Astragalus Stocksii.

\section{Total antioxidant capacity}

Other method which is used to measure the antioxidant activity was Total antioxidant capacity assay by following phosphomolybdenum method. This method is consist of the diminution of Mo (IV) to Mo (V) with the production of green phosphate Mo (V) generally, find out the antioxidant compounds such as phenol, $\alpha$ tocopherol and carotenoids $[24,27]$. Total antioxidant capacity in methanol, Ethanol and
Acetone are shown in figure 3. Graph showed that methanol extract has significantly higher content than those of the ethanol and acetone. Acetone showed lower antioxidant capacity than methanol and ethanol. These observations recommend that methanolic extract of Astragallus Stocksiii is a powerful antioxidant negotiator and can be used for drug development to guard the human body against oxidative damage. 


\section{Al-Nahrain Journal of Science}

ANJS, Vol.24 (3), September, 2021, pp. 16-22

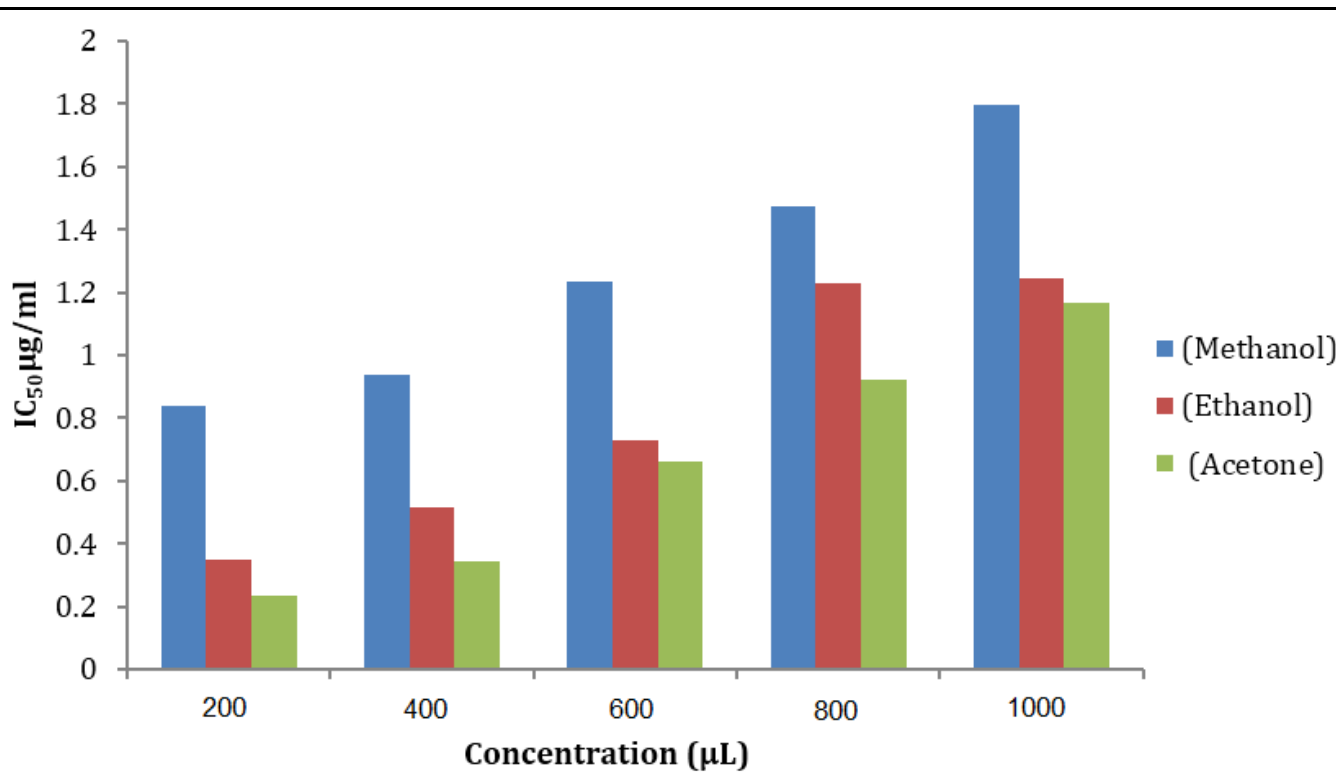

Figure 3. Antioxidant capacity of methanol, ethanol and aceton extracts of Astragalus Stocksii.

\section{Anti-Inflammatory Activity}

Inflammation is a complicated method which is related with the body tissue reactions, injuries and irritation. Inflammation causes various diseases like diabetes, asthema, cancer, arthritis, autoimmune diseases and neurogenerative disorders [25]. The treatment of antiinflammation with steroidal and non steroidal drugs produces severe side effects so in the latest research innovative anti-inflammatory agents have been discovered from the natural sources which are more secure than conventional drugs [16]. In the current research, antiinflammatory activity of Astragallus Stocksiii plant was measured in different solvents via Oxidative Burst Assay. Result showed that methanolic extract has high antiinflammatory activity than ethanol and acetone. It is may be due to the presence of phenolic, alkaloids and flavonoid compounds in plant extract. These evaluations recommend that methnoic extract of Astragallus Stocksiii is the most influential extract and considerable resource of antiinflammatory and antioxidant compounds.

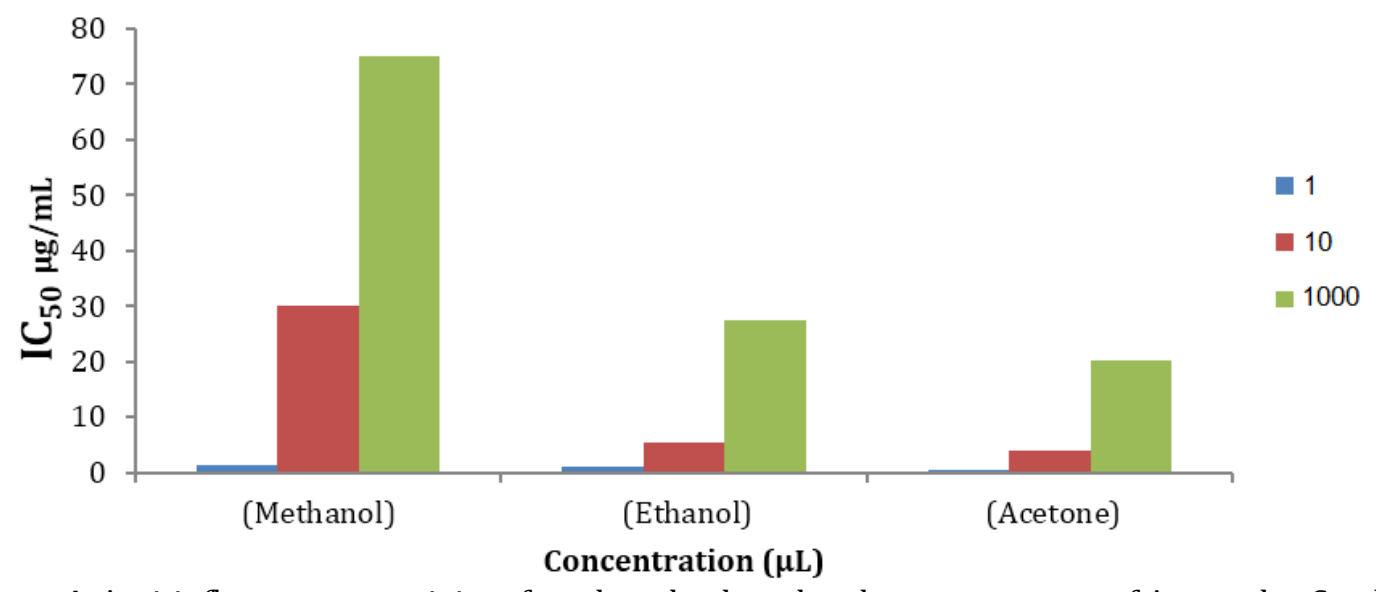

Figure 4. Anti-inflammatory activity of methanol, ethanol and aceton extracts of Astragalus Stocksii.

\section{Conclusion}

The current investugation describes that extraction of Astragallus Stocksiii by utilizing specific solvents (Methanol, Ethanol, Acetone). Amide them methanol was superlative solvent to extricate the these compounds from the Astragallus Stocksiii as it showed highest phenolic contents. The extracts were used to evaluate the antiinflammatory and antioxidant activities as well and compared with other solvents. Methanolic extract demonstrated the high antioxidant and anti-inflammatory activity which shows that methanol is the superlative solvent among the solvents tested to determine the bioactive compounds so plant extract of methanol is a favourable antioxidant and anti- inflammatory representative for the pharmaceutical and nutraceutical industries. 


\section{Al-Nahrain Journal of Science}

ANJS, Vol.24 (3), September, 2021, pp. 16-22

\begin{abstract}
Acknowledgement
The authors would like to express their gratitude to the Department of Biochemistry and Chemistry at the University of Balochistan in Quetta, as well as the Higher Education Commission, for providing all funds and facilities.
\end{abstract}

\section{References}

[1] Kadam S. T. and Pawar A. D.; "Conservation of medicinal plants: A review". Int. Ayurvedic Med. J, 8, 3890-3895, 2020.

[2] Bourezzane S.; Haba H.; Long C. and Benkhaled M.; "Chemical composition and antioxidant activity of Astragalus monspessulanus L. growing in semiarid areas of Algeria". Journal of the Serbian Chemical Society, 83(1), 31-38, 2018.

[3] Zheng W. and Wang S. Y.; "Antioxidant activity and phenolic compounds in selected herbs". Journal of Agricultural and Food Chemistry, 49(11), 5165-5170, 2001.

[4] Pietta P.; Simonetti P. and Mauri P.; "Antioxidant activity of selected medicinal plants". Journal of Agricultural and Food Chemistry, 46(11), 4487-4490, 1998.

[5] Fan Y.; Ren M.; Hou W.; Guo C.; Tong D.; Ma L. and Song X.; "The activation of Epimedium polysaccharidepropolis flavone liposome on Kupffer cells". Carbohydrate polymers, 133, 613-623, 2015.

[6] Zhao Y.; Chen S.; Wang Y.; Lv C.; Wang J. and Lu J.; "Effect of drying processes on prenylflavonoid content and antioxidant activity of Epimedium koreanum Nakai". Journal of food and drug analysis, 26(2), 796806, 2018.

[7] Izuegbuna O.; Otunola G. and Bradley G.; "Chemical composition, antioxidant, anti-inflammatory, and cytotoxic activities of Opuntia stricta cladodes". Plos one, 14(1), e0209682, 2019.

[8] Kamkar A.; "The study of antioxidant activity of essential oil and extract of Iranian Anethum graveloens". The Horizon of Medical Sciences, 15(2), 11-16, 2009.

[9] Valko M.; Leibfritz D.; Moncol J.; Cronin M. T.; Mazur M. and Telser J.; "Free radicals and antioxidants in normal physiological functions and human disease". The international journal of biochemistry \& cell biology, 39(1), 44-84, 2007.

[10] Kamkar A.; Tooriyan F.; Jafari M.; Bagherzade M.; Saadatjou S. and Molaee Aghaee E.; "Antioxidant activity of methanol and ethanol extracts of Satureja hortensis L. in soybean oil". Journal of food quality and hazards control, 1(4), 113-119, 2014.

[11] Zhang L.; Ravipati A. S.; Koyyalamudi S. R.; Jeong S. C.; Reddy N.; Smith P. T. and Wu M. J.; "Antioxidant and anti-inflammatory activities of selected medicinal plants containing phenolic and flavonoid compounds". Journal of Agricultural and Food Chemistry, 59(23), 12361-12367, 2011.
[12] Fürst R. and Zündorf I.; "Plant-derived antiinflammatory compounds: hopes and disappointments regarding the translation of preclinical knowledge into clinical progress". Mediators of inflammation, 2014, $1-9,2014$

[13] Rawdin B.; Mellon S.; Dhabhar F.; Epel E.; Puterman, E.; Su Y. and Hamilton S.; "Dysregulated relationship of inflammation and oxidative stress in major depressio". Brain, Behavior, and Immunity, 31, 143$152,2013$.

[14] Moreno-Quirós C. V.; Sánchez-Medina A.; VázquezHernández M.; Reyes A. G. H. and García-Rodríguez R. V.; "Antioxidant, anti-inflammatory and antinociceptive potential of Ternstroemia sylvatica Schltdl. \& Cham". Asian Pacific journal of tropical medicine, 10(11), 1047-1053, 2017.

[15] Mahdi-Pour B.; Jothy S. L.; Latha L. Y.; Chen Y. and Sasidharan S.; "Antioxidant activity of methanol extracts of different parts of Lantana camara". Asian Pacific journal of tropical biomedicine, 2(12), 960-96, 2012.

[16] Truong D.-H.; Nguyen D. H.; Ta N. T. A.; Bui A. V.; Do T. H. and Nguyen H. C.; "Evaluation of the use of different solvents for phytochemical constituents, antioxidants, and in vitro anti-inflammatory activities of Severinia buxifolia". Journal of food quality, 2019, 1-10, 2019.

[17] Ajanal M.; Gundkalle M. B. and Nayak S. U.; "Estimation of total alkaloid in Chitrakadivati by UVSpectrophotometer". Ancient science of life, 31(4), 198, 2012.

[18] Mesaik M. A.; Azim M. K. and Mohiuddin S.; "Honey modulates oxidative burst of professional phagocytes". Phytotherapy Research: An International Journal Devoted to Pharmacological and Toxicological Evaluation of Natural Product Derivatives, 22(10), 1404-1408, 2008.

[19] Turkmen N.; Sari F. and Velioglu Y. S.; "Effects of extraction solvents on concentration and antioxidant activity of black and black mate tea polyphenols determined by ferrous tartrate and Folin-Ciocalteu methods". Food chemistry, 99(4), 835-841, 2006.

[20] Do Q. D.; Angkawijaya A. E.; Tran-Nguyen P. L.; Huynh L. H.; Soetaredjo F. E.; Ismadji S. and Ju Y.H.; "Effect of extraction solvent on total phenol content, total flavonoid content, and antioxidant activity of Limnophila aromatica". Journal of food and drug analysis, 22(3), 296-30, 2014.

[21] McDonald S.; Prenzler P. D.; Antolovich M. and Robards K.; "Phenolic content and antioxidant activity of olive extracts". Food chemistry, 73(1), 73-84, 2001.

[22] Ngo T. V.; Scarlett C. J.; Bowyer M. C.; Ngo P. D. and Vuong Q. V.; "Impact of different extraction solvents on bioactive compounds and antioxidant capacity from the root of Salacia chinensis L.". Journal of food quality, 2017, 1-9, 2017. 


\section{Al-Nahrain Journal of Science}

ANJS, Vol.24 (3), September, 2021, pp. 16-22

[23] Chao P.-Y.; Lin S.-Y.; Lin K.-H.; Liu Y.-F.; Hsu J.-I.; Yang C.-M. and Lai J.-Y.; "Antioxidant activity in extracts of 27 indigenous Taiwanese vegetables Nutrients". 6(5), 2115-2130, 2014.

[24] Maswada H.: "Assessment of Total Antioxidant Capacity and Antiradical Scavenging Activity of Three Egyptian Wild Plants". Journal of Medical Sciences (Faisalabad), 13, 546-554. doi: 10.3923/jms.2013.546.554, 2013.

[25] Oyeleke S. A.; Ajayi A. M.; Umukoro S.; Aderibigbe A. and Ademowo O. G.; "Anti-inflammatory activity of Theobroma cacao L. stem bark ethanol extract and its fractions in experimental models". Journal of Ethnopharmacology, 222, 239-248, 2018.

[26] Nisa K. U. and Khan N.; "Detection of Heavy metals in Fruits and Vegetables available in the Market of Quetta city". Al-Nahrain Journal of Science, 23(1), 4756, 2020.

[27] Tareen A. H.; Mandokhail, A.; Khan, N.; Tariq, S. and Kakar, N.; "Determination of Antioxidants by Four Different Methods in Medicinally Important Plant Ebenus Stellata of Balochistan". Al-Nahrain Journal of Science, 23(4), 13-18, 2020.

[28] Jasim H. H. and Abed N. K.; "Determination of Ibuprpfen in Aqueaus Solutions and Pharmacetical Preparations by UV-VIS Spectrophotometric". AlNahrain Journal of Science, 18(2), 1-9, 2015.

[29] Muhram J.; "Effect of rosemary (Rosmarinus officinalis L.) tissue extracts on the growth of some skin infectious microorganisms". (Doctoral dissertation, Ministry of Higher Education), 1-115, 2009. 